\title{
Sleep Disorders in Students during the COVID-19 Pandemic
}

\section{Geórgia Saad1, Vítor Cruz Rosa Pires de Souza1, Joaquim Borges de Menezes Neto², Eduardo de Sousa Martins e Silva ${ }^{3}$, José Carlos Rosa Pires de Souza ${ }^{4}$}

\author{
${ }^{1}$ University for the Development of the State and the Pantanal Region (Uniderp), Campo Grande, MS, Brazil \\ ${ }^{2}$ Federal University of Mato Grosso do Sul (UFMS), Campo Grande, MS, Brazil \\ ${ }^{3}$ Federal University of Triângulo Mineiro (UFTM), Uberaba, MG, Brazil \\ ${ }^{4}$ State University of Mato Grosso do Sul (UEMS), Campo Grande, MS, Brazil \\ Email: georgias1998@hotmail.com,crpsvitor@gmail.com, joaquimparanhos@outlook.com,eduardosousa25@gmail.com, \\ josecarlossouza@uol.com.br
}

How to cite this paper: Saad, G., de Souza, V. C. R. P., Neto, J. B. de M., e Silva, E. de S. M., \& de Souza, J. C. R. P. (2021). Sleep Disorders in Students during the COVID-19 Pandemic. Creative Education, 12, 378-390. https://doi.org/10.4236/ce.2021.122027

Received: January 24, 2021

Accepted: February 19, 2021

Published: February 22, 2021

Copyright () 2021 by author(s) and Scientific Research Publishing Inc. This work is licensed under the Creative Commons Attribution International License (CC BY 4.0).

http://creativecommons.org/licenses/by/4.0/

\section{(c) (i) Open Access}

\begin{abstract}
Introduction: The current pandemic has caused several social and behavioural changes at a national level. These changes had a negative impact on mental health and sleep quality. Sleep is one of the main regulators and repairers of the body and is involved in both cognition and memory as well as immunity and hormonal balance. Objective: This study seeks to identify the main sleep disorders aggravated by the COVID-19 Pandemic and their consequences to the population. Methods. A bibliographic narrative review was made with articles dating from the last 5 years (2016-2021), which were extracted from the National Library of Medicine (PubMed), Scientific Electronic Library Online (SciELO), Latin American and Caribbean Literature in Health Sciences (LILACS) and "Google Academic" databases, using the following keywords and descriptors in Portuguese and English; "Sleep/Sono", "Sleep Disorders/Distúrbios do Sono", "Insomnia", "Pandemic/Pandemia", "COVID-19", "Immunity/Imunidade", "Viral Infections/Infecções virais", "Coronavírus", "Sleep-Wake Cycle Rhythm/Ritmo ciclo-vigília", "Biological Clocks/Relógios biológicos" and the Boolean operator "and/e". Results and Discussion: Insomnia and sleep-wake cycle changes have been quite evident among the population and were mainly aggravated by the increase of anxiety and depressive symptoms taking place during the pandemic. Students have gone through major routine changes disrupting their daily activities, such as physical activities, class schedules, and use of electronic equipment, which in turn accentuate sleep problems affecting their academic performance and learning. Conclusion: The pandemic has changed many habits and routines, with students among those who were affected the most, both in terms of psychological disorders affecting quality of sleep, as well as irregular sleep that
\end{abstract}


itself influences cognition and learning. Insomnia has proved to be frequent in the population, and its effects on the body, especially regarding the immune system and emotional regulation are not favourable for confronting the new coronavirus.

\section{Keywords}

Pandemic, Insomnia, Students, Rhythm Circadian, Sleep

\section{Introduction}

The current COVID-19 pandemic caused by a new coronavirus (SARS-CoV-2), regards the spread of an acute and contagious respiratory disease. Because it is new, the human being has no previous immunity and its spread has taken global dimensions, resulting in a great economic, social and public health national crisis. Currently, a total of 89,731,755 cases worldwide and 8,075,998 cases in Brazil (Silva et al., 2021) were reported by the Ministry of Health and the World Health Organization (WHO).

Several measures have been taken by the Brazilian government to avoid contamination and a worsening in the number of cases. The use of masks, alcohol gel and social isolation were among those most evidenced by the media. The latter displayed a great impact on the life of the population in several aspects, mainly on mental health. Since the vast majority of the Brazilian population adhered to self-isolation, leaving home only for essential activities, a study carried out in Brazil, with individuals from different states, showed that more than half of the participants had anxious feelings after the arrival of the pandemic, $40.2 \%$ felt depressed and $44.9 \%$ started having problems with sleep (Almeida et al., 2020). Such circumstances can also be seen in other studies; a survey published by Ciencia \& Saúde Coletiva magazine in June 2020, confirms that the vast majority of Brazilians had increased levels of depressive symptoms, anxiety and changes in hours of sleep after the outbreak of COVID-19. These are major stress factors that worsen quality of life (Bezerra et al., 2020).

Sleep is a physiological process that seeks regulation and repair of the body, playing a key role in many of its functions. Recent studies show a great association between sleep deprivation and increased blood pressure, with both linked to an increased activity in the sympathetic nervous system and kidney sodium retention, as well as because of the resulting emotional changes such as irritability, pessimism and stress which impair the implementation of a healthy lifestyle (Santos \& Souza, 2021). The concentration level of various hormones is also influenced by sleep, such as increased release of growth hormone (GH) and thyroid stimulant (TSH) in the non-REM phase, which are essentials for body growth, and the release of cortisol in the REM phase, essential for the metabolization of glucose, proteins and lipids (El Halal \& Nunes, 2019).

In addition, the link between sleep and immune system quality has been well 
evident in recent years. A low quality of sleep negatively affects the human immune system, contributing to the implantation of an inflammatory condition in the body and worsening antiviral responses. This situation can be seen in a series of sleep disorders described by the 2014 International Classification of Sleep Disorders divided into seven major groups: insomnia disorders, sleep related breathing disorders, central hypersomnia disorders, circadian rhythm sleep-wake disorders, parasomnia disorders, sleep related movement disorders, among others.

The fear surrounding the coronavirus disease, the emotional stress of isolation and the economic burden brought on by the situation, make this environment favourable for an increase of anxious and depressive symptoms in the population. Therefore, sleep patterns and their efficiency are affected. Those which are most widely seen in the current panorama are insomnia, itself quite associated with great emotional stress, and out of phase sleep caused by longer periods of time using social media at night, therefore altering the circadian rhythm of the normal brain. Both negatively affect the regulation of bodily organic functions as well as emotion and cognition, since sleep is the main factor for memory consolidation. Knowing which circumstances are related to sleep disorders is of great importance for the development of therapies in the future. The Brazilian Consensus on Insomnia has already presented support strategies for individuals who present such difficulties (Nami et al., 2020; Voitsidis et al., 2020).

In this context, this study seeks to discuss sleep disorders during the COVID-19 pandemic, its main causes and relationship with the higher levels of depression and anxiety during this period. Emphasizing, also, its consequences for the quality of life and function of the organism, taking into account the immune system, the hormones cortisol and melatonin, the function of memory, among other outcomes for the general population and especially, for student.

\section{Methodology}

Qualitative and descriptive research were made through a narrative or what is also called a traditional bibliographic review. This effort sought to analyse and discuss theoretical aspects involving facts and propositions that emerge from changes in scientific concepts (Pereira et al., 2018). It is important to stress that this type of review is also essential for deepening the debate and exposing diversified visions regarding the theme to be further developed (Depolito et al., 2020).

The search for primary studies occurred from scientific articles from the last 5 years (2016-2021), in Portuguese and English in the National Library of Medicine (PubMed), Scientific Electronic Library Online (SciELO), Latin American and Caribbean Health Sciences Literature (LILACS) and "Google Academic", using the following terms as keywords and descriptors, both in Portuguese and English; "Sono/Sleep", "Disúrbios do sono/Sleep Disorders", "Insomnia", "Pandemia/Pandemic”, "COVID-19”, "Imunidade/Immunity”, "Infecçõesvirais/Viral Infections", "Coronavírus", "Ritmociclo-vigília/Sleep-Wake Cycle Rhythm", 
"Relógiosbiológicos/Biological Clocks" and the Boolean operator "e/and". The following inclusion criteria were adopted: 1) original articles (experimental studies, randomized clinical trials, case-control studies); 2) articles published in Portuguese and English; 3) articles published in the year 2016 to 2021; 4) articles that had in the title and/or abstract the descriptors used in the search; 5) articles that could provide basis for a narrative review.

The research was completed in January 2021 and, in total, 43scientific articles were obtained. A dynamic reading of the abstracts of each article that met the inclusion criteria was performed and then only those that could contribute to the study objective were selected. Finally, 41 publications proceeded to a thorough reading, with the purpose of extracting the data from each research and, later, these were categorized according to the topics of interest for this review. Then, the results were discussed.

\section{Results and Discussion}

\subsection{Sleep and Its Disorders}

Sleep disorders are characterized as harmful alterations in quality, duration, and behaviour related to sleep; they represent a wide range of disorders and pathologies that negatively affect good sleep and consequently, many other daily activities (Pacheco, 2020). In this sense, sleep-related disorders may manifest themselves mainly as complaints related to excess or lack of sleep as well as abnormal movements during sleep (Pavlova \& Latreille, 2019).

Insomnia is the most common among sleep disorders, with estimates of its prevalence ranging from $10 \%-40 \%$ of the world population (Bhaskar, Hemavathy, \& Prasad, 2016). Elderly people, women and especially individuals suffering from psychic disorders are more likely to develop insomnia, being therefore considered risk groups (Grandner, 2017). Due to the role of sleep in emotional stabilization and mood regulation, people suffering from insomnia are more at risk of developing anxiety and depression disorders, which, in turn, may aggravate insomnia, worsening the overall picture (Li et al., 2016).

The diagnosis of insomnia is based on two aspects: there is an inability to sleep (difficulty in its genesis or in its maintenance) despite the adequate opportunities for a normal sleep, and daily loss resulting from poor quality or insufficient duration of sleep (American Academy of Sleep Medicine, 2014). Adverse health effects promoted by both acute and chronic sleep deprivation while associated with the high prevalence of insomnia in the population, reveal the social, economic and health importance of treating this sleep disorder properly.

The numerous physiological processes that occur in the human body are largely regulated by the circadian rhythm, an important temporal marker that influences the sleep-wake cycle, as well as cycles related to body temperature and hormone release (Farhud \& Aryan, 2018). In this sense, life styles, environmental factors such as prolonged or scarce exposure to both sunlight or artificial light as well as seasons among other factors can compromise the circadian cycle 
function, facilitating the occurrence of sleep disorders related to a delay or an advance in rhythm (Pavlova \& Latreille, 2019).

Regarding sleep disorders related to an advance in the circadian cycle, there is a tendency for the individual to sleep earlier, which facilitates the appearance of late insomnia, a type of insomnia characterized by the interruption of sleep before the stipulated time, usually at dawn, with an inability to return to sleep. However, in a sleep disorder related to a delay in the circadian cycle, there is a predisposition to sleep later, which can also facilitate the occurrence of early type insomnia, which is characterized by difficulty in starting to sleep (American Academy of Sleep Medicine, 2014). It is estimated that $10 \%$ of chronic insomnia cases occur due to a delay in the circadian cycle (Flynn-Evans et al., 2017).

Abrupt changes in routine such as travel along time zones, decreased exposure to sunlight or the intense use of certain types of artificial light during the night may modify the circadian rhythm (Farhud \& Aryan, 2018). This contributes to night workers, travellers and people in irregular and private routines being groups at risk for such sleep related disorders (Pavlova \& Latreille, 2019).

\subsection{Anxiety, Depression and Its Repercussions on Sleep during the COVID-19 Pandemic}

In 2020, during the COVID-19 pandemic, additionally to the scientific forces that emerged trying to understand and explain this new virus, as well as the efforts of infectology in the fight against SARS-CoV-2, another area that also gained a leading role was that of psychiatry. After all, the world population had to face not only the new variant of the coronavirus, but all the psychological problems derived from this biological battle, such as the uncertainty of contagion, the degree of morbidities caused by the virus and social isolation. Several efforts and contributions came forth to better understand the psychological impact of the pandemic.

A study on the mental health of the Jordanian population during the pandemic measured the levels of anxiety, depression and sleep problems, by means of metrics used internationally. For anxiety the "General Anxiety Disorder 7-item" (GAD-7) was used; for depression the "Center for Epidemiologic Studies Depression Scale" was used; and for sleep health the "Pittsburgh Sleep Quality Index" was used. The results showed high levels of both depression, anxiety and sleep problems, and a correlation between them. Approximately one third of the participants faced some type of anxiety and almost half reported depressive symptoms as well as symptom of insomnia during the referred period (Al-Ajlouni et al., 2020).

These increments can also be seen in the Moroccan population. A survey to assess the weight of the pandemic in the psychological state and in sleep, showed an increase of sleeping problems in $56.0 \%$ of the population, being accompanied by aggravation of anxious and depressive symptoms. In China, such percentage also increased by $18.1 \%, 35.1 \%$ and $20.1 \%$, respectively, on the general population (Janati Idrissi et al., 2020). Taking into account medical health care workers 
in China, which are exposed to a persistent source of distress, even higher prevalence rates of severe insomnia, anxiety and depression were found, due mainly to difficulties of being safe at work (Zhang, Wang, Yin et al., 2020).

A Brazilian survey, which analysed a sample of 45,161 participants from all macro-regions in the country, reported that during the pandemic, depressive and anxious feelings reached a percentage of $40 \%$ comprising more than $50 \%$ of Brazilians in this study, respectively. In addition, the study came to the conclusion that of all the participants who did not have previous sleep problems, more than $40 \%$ came to develop them, and for those who already had these disorders, almost half had their insomnia worsened (Barros et al., 2020).

This increment in the levels of depression and anxiety in the world population is important to understand the increase in cases of sleep problems (Figure 1), since there is a strong correlation between them. According to the DSM- 5 criteria, both Major Depression Disorder and Generalized Anxiety Disorder have problems with sleep as one of the symptoms. Al-Ajlouni et al. (2020), among other studies, discusses this same relationship. The exact explanation for the pathophysiology behind this is still uncertain, but some factors may influence the prevalence of insomnia. It is believed that monoamine deregulation, caused by depression, may also affect REM sleep, and consequently generate problems in sleep quality. Voitsidis et al. (2020), came to the conclusion that factors such as monoamine dysregulation, inflammatory and genetic factors, as well as deregulation of the circadian cycle are behind the relationship between depression and insomnia.

Two additional studies, Voitsidis et al. (2020) and Kokou-kpolou et al. (2020) concluded that feelings of loneliness and concern are major causes of insomnia and are related in a two-way manner. The feeling of concern induces anxiety and deregulation in the heart rhythm, promoting low quality sleep, with feelings of loneliness contributing to the sleep disorder as it hinders social coexistence. Therefore, to understand the increased prevalence of insomnia during the pandemic, factors such as health concerns, financial concerns, uncertainties and changes in the pace of social life must be taken into account for the higher level of stress and consequently, the increase in sleep problems (Voitsidis et al., 2020).

\begin{tabular}{|c|c|c|c|}
\hline Total study population & $\begin{array}{c}\text { Experienced Depressive } \\
\text { Symptoms }\end{array}$ & $\begin{array}{c}\text { Experienced Anxiety } \\
\text { Symptoms }\end{array}$ & $\begin{array}{c}\text { Experienced Sleeping } \\
\text { Problems }\end{array}$ \\
\hline 45.161 Brazilian & $40.4 \%$ & $52.6 \%$ & $43.5 \%$ \\
\hline 827 Moroccan & $35.6 \%$ & $29.5 \%$ & $56 \%$ \\
\hline & & & \\
7.236 Chinese & $20.1 \%$ & $35.1 \%$ & $18.1 \%$ \\
\hline
\end{tabular}

Figure 1. Increased percentages of depressive symptoms, anxiety and problems with sleep in the populations of the studies described above. 
Identifying the main reasons for sleep problems is of utmost importance since their abnormalities are major contributors for triggering ideation and suicide attempts. The treatment for insomnia stands out due to its exponential growth during the pandemic, and must have its causes further investigated by doctors (Sher, 2020). A study with university students reported that insomnia is highly related to the appearance of suicidal thoughts, because it causes an emotional and biological circadian deregulation in human beings (Russell et al., 2019). Staying awake at night demonstrates greater delta wave activity in the prefrontal cortex which is also seen in patients diagnosed with depression, and the night period is the lowest point where positive thoughts are found. Taking into account such circumstances, staying awake at the time you should be asleep can open a dangerous window for suicidal thoughts and attempts (Perlis et al., 2016).

In a US study, which assessed the relationship between concerns about the new coronavirus, suicidal ideation and insomnia, through the application of three standardized questionnaires, Insomnia Severity Index (ISI), Patient Health Questionnaire-9 (PHQ-9) and a modified scale of concern about the COVID-19 pandemic, it was found that there is a direct relationship between insomnia and increased suicidal ideation, regardless of levels of concern about the virus, thus confirming an intimate and exclusive relationship between this sleep disorder and suicidal thoughts (Killgore et al., 2020).

In addition, other elements should be pointed out as reasons to seek treatment for sleeping problems. The increase in pro-inflammatory mediators, mainly IL-1, IL-6 and TNF-alpha, and reduction in number and activity of immune system cells, such as the NK cell, T-auxiliary lymphocytes (CD4+, CD8+) and $\mathrm{T}$-cytotoxic lymphocytes, are consequential of irregular sleep and promote an inefficient environment for infectious agents (Asif, Iqbal, \& Nazir, 2017). It was also found that the great replication of SARS-CoV-2 can lead to an exuberant discharge of inflammatory responses, contributing to the pathophysiology of this disease, which can be avoided, at least in part, through regularization of sleep (Fu, Cheng, \& Wu, 2020).

\subsection{Sleep Disorders in Students during the COVID-19 Pandemic}

The pandemic has led to major changes in human behaviour in general. Taking into account students, who suffered drastic adaptation in the form of learning, given the transition from face-to-face classes to online classes, it could not be otherwise. According to a survey published by Current Biology Magazine in June 2020, an increase in students' sleep time after the start of online classes has been noticed. However, sleep start times were generally delayed in every day of the week and, as we already know, this can be associated with poorer health (Wright Jr. et al., 2020).

In addition, morning waking hours were postponed as well, causing no change in the amount of total sleep acquired per night. The suspicion would be that students adjusted their work to their individual sleep chronotypes given that without 
strict schedules they could follow their own biological rhythm. Sleep-wake schedules are organized by the time spent awake and by the fixed times to carry out the day's activities, such as waking up, eating, studying, interacting with family members, among others. Exposure to the sun plays a crucial role in such functioning, yet, due to the isolation, such activity is impaired. Researches confirm that the circadian rhythm of sleep changes significantly after several days of confinement, becoming out of sync with the outside world (Morin et al., 2020).

The increase in the use of electronic equipment during the lockdown can also cause problems in the regulation of the sleep-wake cycle, and its latency (time it took students to fall asleep) (Romero-Blanco et al., 2020). Melatonin, synthesized from serotonin, is an important regulator of the cycle-circadian. Produced during the night, it serves as a sleep neuroendocrine signal and when suppressed by the action of light, can prolong the ability to remain alert at night. That said, the high intensity of light from electronic devices, causes an inhibition of its synthesis, triggering sleep problems and intensifying the symptoms of insomnia in students during the pandemic (Oliveira, 2016). Moreover, the higher release of dopamine that occurs when one is in the virtual world compared to the real one can be a great trigger for mood disorders, such as anguish, irritation and, especially, depression (Souza \& Miranda, 2018).

Furthermore, isolation has also facilitated an adoption of sedentary life habits by adolescents and young adults. There was a reduction in the amount of physical exercises as opposed to the increase in the time spent on electronic equipment (Brito et al., 2020). The 2018 Physical Activity Guidelines for Americans of the U.S. Department of Health and Human Services (2018) recommends $60 \mathrm{mi}-$ nutes of physical exercise daily for children and adolescents, however, due to the current situation, many young people have experienced difficulties in reaching this goal (Brito et al., 2020). It is already known that the practice of exercises influences the quality of sleep, especially in latency and number of daily hours. Exercise causes an increase in GH release during the night, increasing the sleep of slow waves in time and intensity (stage 3 and stage 4 sleep), thus improving its quality (Oliveira, 2016). Moreover, daily physical activity is associated with a lower risk of psychiatric distress, minimizing negative thoughts caused by the disease and social distancing (Zhang Zhang, Ma, \& Di, 2020).

It was found that, young people under 35 years of age who follow updates on COVID-19 for more than three hours a day, either through the news or by mobile devices, have higher levels of anxiety and depression, which lead to an increase in cortisol levels in the body and a reduction in melatonin synthesis, causing changes in a normal biological sleep rhythm (Marelli et al., 2020). It was identified as one of the main causes of the increase in depressive and anxious symptoms in students during this period, not only the follow-up of positive cases and death numbers by COVID-19 but also the socioeconomic situation (Maia \& Dias, 2020). The uncertainty of being able to afford college expenses, concerns about family and friends health and worry about the impact of the pandemic on students' future careers has caused a great deal of stress, especially in university 
students who live alone and far from their families, due to reduced social interactions and lack of social support. Graduated students are also suffering from the situation because of the difficulty in finding jobs and fulfilling their academic duties (Islam et al., 2020; Elmer et al., 2020).

Anxiety and depression are associated with a worsening of insomnia symptoms which were widely discussed in the topics above. In students, greater difficulties were seen in the initial stages of sleep and although the total sleep hours were not decreased, their quality worsened (Marelli et al., 2020). This situation can be seen in a series of studies with university students, a survey conducted with nursing college students in Spain, detected major changes in their sleep patterns after the outbreak of COVID-19. Despite the time spent in bed having increased the proportion of time really dedicated to sleep was much less, indicating low sleep efficiency and difficulty falling asleep. Gender differences were also found in the present study, with women being the most affected by the pandemic (Romero-Blanco et al., 2020). Coping strategies to minimize these stressful symptoms are already being recommended by the World Health Organization (WHO) (Średniawa et al., 2019; Maia \& Dias, 2020; World Health Organization, 2020).

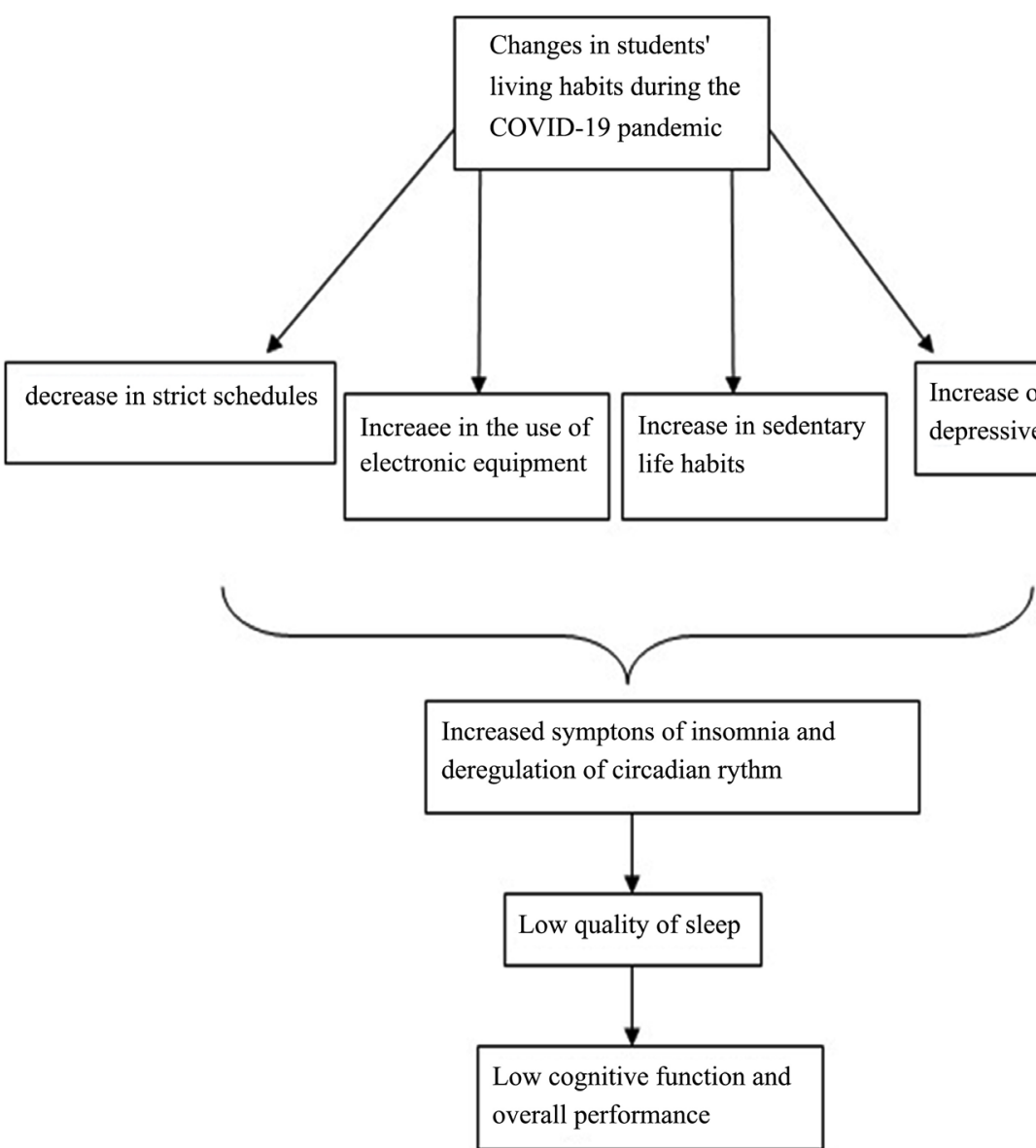

Figure 2. Changes in students living habits during COVID-19 and its impacts on sleep and performance. 
Insomnia and deregulation of the circadian rhythm of sleep can also negatively affect students' cognitive function and overall performance. During sleep, there is high activity in the hippocampus for transferring information to the cerebral cortex and long term storage of daily processes, consolidating long-term memory.

Knowing that non-REM sleep helps in the consolidation of declarative memories while REM sleep does so in procedural memory, and that they are responsible for the consolidation of the information obtained, it can be said that alterations in both phases cause problems in the assimilation of contents and worsened learning. Moreover, the quality of sleep compromises the alert state and the level of daytime concentration while it increases the level of stress, making the assimilation of new contents difficult (Figure 2) (Batista et al., 2018).

\section{Conclusion}

The COVID-19 pandemic has changed many habits and life routines of the general population, affecting their biological clocks and especially the sleep-wake cycle. The implications of this disorder affect several points in human homeostasis, such as the growth hormone, which is mostly produced during sleep and will not be able to properly perform its functions due to involuntary sleep deprivation, and the increase in inflammatory mediators, that leads to a dangerous pro-inflammatory state for a disease whose pathophysiology seems to be related to exacerbated inflammatory responses. In addition, the decrease in the activity of immune system causes greater vulnerability for the individual, something extremely dangerous in a pandemic of a potentially lethal virus.

Apart from this, another harmful implication to individuals affected by sleep disorders is related to cognitive aspects. The symptoms of anxiety and depression have grown exponentially in the population, and there has certainly been a progressive increase in medical appointments due to complaints of sleeping problems in general, especially insomnia. Among the most affected are students as a whole, since memory is solidified during sleep, insomnia affects not only the assimilation of the new content, by decreasing the quality of attention, but also the consolidation of these contents, by affecting both REM and non-REM sleep. Furthermore, the effective area is also affected by this disorder, disturbing social life and predisposing to loneliness.

Finally, no less important implication of insomnia is related to the increase in suicidal ideations. Studies prove and explain this dangerous relationship, adding yet another reason to investigate and combat this extremely harmful condition that negatively interferes with the quality of life of the population and mainly, students.

\section{Conflicts of Interest}

The authors declare no conflicts of interest regarding the publication of this paper. 


\section{References}

Al-Ajlouni, Y. A., Park, S. H., Alawa, J., Shamaileh, G., Bawab, A., El-Sadr, W. M., \& Duncan, D. T. (2020). Anxiety and Depressive Symptoms Are Associated with Poor Sleep Health during a Period of COVID-19-Induced Nationwide Lockdown: A Cross-Sectional Analysis of Adults in Jordan. BMJ Open, 10, e041995.

Almeida, W. da S., Szwarcwald, C. L., Malta, D. C., Barros, M. B. de A., Souza Júnior, P. R. B., Azevedo, L. O. et al. (2020). Mudanças nas condições socioeconômicas e de saúde dos brasileiros durante a pandemia de COVID-19. Revista Brasileira de Epidemiologia, 23, e200105. https://doi.org/10.1590/1980-549720200105

American Academy of Sleep Medicine (2014). International Classification of Sleep Disorders: Diagnostic and Coding Manual (3rd ed.). Darien, IL: American Academy of Sleep Medicine.

American College of Sports Medicine (ACSM) (2020). Staying Active during the Coronavirus Pandemic. https://www.exerciseismedicine.org/assets/page_documents/EIM_Rx\%20for\%20Health \%20Staying\%20Active\%20During\%20Coronavirus\%20Pandemic.pdf

Asif, N., Iqbal, R., \& Nazir, C. F. (2017). Human Immune System during Sleep. American Journal of Clinical and Experimental Immunology, 6, 92-96.

Barros, M. B. A. et al. (2020). Report of Sadness/Depression, Nervousness/Anxiety and Sleeping Problems in the Brazilian Adult Population during the COVID-19 Pandemic. Epidemiologia e Serviços de Saúde, 29, e2020427.

Batista, G. A., Silva, T. N., Oliveira, M. R., Diniz, P. R. B, Lopes, S. S., \& Oliveira, L. M. F. T. (2018). Association between the Perception of the Quality of Sleep and the Assimilation of the Content Addressed in the Classroom. Revista Paulista de Pediatria, 36, 315-321. https://doi.org/10.1590/1984-0462/;2018;36;3;00008

Bezerra, A. C. V., Silva, C. E. M., Soares, F. R. G., \& Silva, J. A. M. (2020). Fatores associados ao comportamento da população durante o isolamento social na pandemia de COVID-19. Ciência \& Saúde Coletiva, 25, 2411-2421.

https://doi.org/10.1590/1413-81232020256.1.10792020

Bhaskar, S., Hemavathy, D., \& Prasad, S. (2016). Prevalence of Chronic Insomnia in Adult Patients and Its Correlation with Medical Comorbidities. Journal of Family Medicine and Primary Care, 5, 780-784. https://doi.org/10.4103/2249-4863.201153

Brito, L. M. S., Boguszewski, M. C. S., Souza, M. T. R., Martins, F., Mota, J., \& Leite, N. (2020). Indoor Physical Activities, Eating and Sleeping Habits among School Adolescents during COVID-19 Pandemic. Revista Brasileira de Atividade Física \& Saúde, 25, e0117. https://doi.org/10.12820/rbafs.25e0117

Depolito, S. C. P., Moraes, L. L., Siqueira, W. G., Sales Baquião, L. M., Januário, G. C., \& Morceli, G. (2020). Performance of the Nursing Team in Front of Early Weaning: A Narrative Review. Saúde Coletiva, 10, 2915-2924.

El Halal, C. S., \& Nunes, M. L. (2019). Sono e desenvolvimento pondero-estatural. Jornal de Pediatria, 95, S2-S9. https://doi.org/10.1016/j.jped.2018.10.009

Elmer, T., Mepham, K., \& Stadtfeld, C. (2020). Students under Lockdown: Comparisons of Students' Social Networks and Mental Health before and during the COVID-19 Crisis in Switzerland. PLOS ONE, 15, e0236337. https://doi.org/10.1371/journal.pone.0236337

Farhud, D., \& Aryan, Z. (2018). Circadian Rhythm, Lifestyle and Health: A Narrative Review. Iranian Journal of Public Health, 47, 1068-1076.

Flynn-Evans, E. E., Shekleton, J. A., Miller, B., Epstein, L. J., Kirsch, D., Brogna, L. A. et 
al. (2017). Circadian Phase and Phase Angle Disorders in Primary Insomnia. Sleep, 40, zsx163. https://doi.org/10.1093/sleep/zsx163

Fu, Y., Cheng, Y., \& Wu, Y. (2020). Understanding SARS-CoV-2-Mediated Inflammatory Responses: From Mechanisms to Potential Therapeutic Tools. Virologica Sinica, 35, 266-271. https://doi.org/10.1007/s12250-020-00207-4

Grandner, M. A. (2017). Sleep, Health, and Society. Sleep Medicine Clinics, 12, 1-22. https://doi.org/10.1016/j.jsmc.2016.10.012

Islam, M. A., Barna, S. D., Raihan, H., Khan, M. N. A., \& Hossain, M. T. (2020). Depression and Anxiety among University Students during the COVID-19 Pandemic in Bangladesh: A Web-Based Cross-Sectional Survey. PLoS ONE, 15, e0238162. https://doi.org/10.1371/journal.pone.0238162

Janati Idrissi, A., Lamkaddem, A., Benouajjit, A., Ben El Bouaazzaoui, M., El Houari, F., Alami, M. et al. (2020). Sleep Quality and Mental Health in the Context of COVID-19 Pandemic and Lockdown in Morocco. Sleep Medicine, 74, 248-253. https://doi.org/10.1016/j.sleep.2020.07.045

Killgore, W., Cloonan, S. A., Taylor, E. C., Fernandez, F., Grandner, M. A., \& Dailey, N. S. (2020). Suicidal Ideation during the COVID-19 Pandemic: The Role of Insomnia. Psychiatry Research, 290, Article ID: 113134. https://doi.org/10.1016/j.psychres.2020.113134

Kokou-Kpolou, C. K., Megalakaki, O., Laimou, D., \& Kousouri, M. (2020). Insomnia during COVID-19 Pandemic and Lockdown: Prevalence, Severity, and Associated Risk Factors in French Population. Psychiatry Research, 290, Article ID: 113128. https://doi.org/10.1016/j.psychres.2020.113128

Li, L., Wu, C., Gan, Y., Qu, X., \& Lu, Z. (2016). Insomnia and the Risk of Depression: A Meta-Analysis of Prospective Cohort Studies. BMC Psychiatry, 16, Article No. 375. https://doi.org/10.1186/s12888-016-1075-3

Maia, B. R., \& Dias, P. C. (2020). Ansiedade, depressão e estresse em estudantes universitários: O impacto da COVID-19. Estudos de Psicologia (Campinas), 37, e200067. https://doi.org/10.1590/1982-0275202037e200067

Marelli, S., Castelnuovo, A., Somma, A., Castronovo, V., Mombelli, S., Bottoni, D. et al. (2020). Impact of COVID-19 Lockdown on Sleep Quality in University Students and Administration Staff. Journal of Neurology, 268, 8-15. https://doi.org/10.1007/s00415-020-10056-6

Morin, C. M., Carrier, J., Bastien, C., Godbout, R., \& Canadian Sleep and Circadian Network (2020). Sleep and Circadian Rhythm in Response to the COVID-19 Pandemic. Canadian Journal of Public Health, 111, 654-657. https://doi.org/10.17269/s41997-020-00382-7

Nami, M., Mehrabi, S., Kamali, A. M., Kazemiha, M., Carvalho, J., Derman, S. et al. (2020). A New Hypothesis on Anxiety, Sleep Insufficiency, and Viral Infections; Reciprocal Links to Consider in Today's "World vs. COVID-19" Endeavors. Frontiers in Psychiatry, 11, Article ID: 585893. https://doi.org/10.3389/fpsyt.2020.585893

Oliveira, S. J. R. (2016). Sono, Melatonina e Exercício Físico [Sleep, Melatonin and Physical Exercise]. Projeto de pós-graduação, Porto, Portugal: Universidade Fernando Pessoa.

Pacheco, D. (2020). Sleep Disorders. Sleep Foundation Org. https://www.sleepfoundation.org/sleep-disorders

Pavlova, M. K., \& Latreille, V. (2019). Sleep Disorders. The American Journal of Medicine, 132, 292-299. https://doi.org/10.1016/j.amjmed.2018.09.021

Pereira, A. S., Shitsuka, D. M., Parreira, F. J., \& Shitsuka, R. (2018). Metodologia da pesquisa 
científica [Scientific Research Methodology] (e-book). Santa Maria Ed., UAB/NTE/UFSM. https://repositorio.ufsm.br/bitstream/handle/1/15824/Lic_Computacao_Metodologia-P esquisa-Cientifica.pdf?sequence $=1$

Perlis, M. L., Grandner, M. A., Chakravorty, S., Bernert, R. A., Brown, G. K., \& Thase, M. E. (2016). Suicide and Sleep: Is It a Bad Thing to be Awake When Reason Sleeps? Sleep Medicine Reviews, 29, 101-107. https://doi.org/10.1016/j.smrv.2015.10.003

Romero-Blanco, C., Rodríguez-Almagro, J., Onieva-Zafra, M. D., Parra-Fernández, M. L., Prado-Laguna, M., \& Hernández-Martínez, A. (2020). Sleep Pattern Changes in Nursing Students during the COVID-19 Lockdown. International Journal of Environmental Research and Public Health, 17, 5222. https://doi.org/10.3390/ijerph17145222

Russell, K., Allan, S., Beattie, L., Bohan, J., MacMahon, K., \& Rasmussen, S. (2019). Sleep Problem, Suicide and Self-Harm in University Students: A Systematic Review. Sleep Medicine Reviews, 44, 58-69. https://doi.org/10.1016/j.smrv.2018.12.008

Santos, E. S. G., \& Souza, O. F. (2021). Evidence of the Association between Sleep Duration and Blood Pressure in Adolescents: A Systematic Review. Revista Paulista de Pediatria, 39, e2019225. https://doi.org/10.1590/1984-0462/2021/39/2019225

Sher, L. (2020). COVID-19, Anxiety, Sleep Disturbances and Suicide. Sleep Medicine, 70, 124. https://doi.org/10.1016/j.sleep.2020.04.019

Silva, F. C., Zamprogna, K. M., Souza, S. S., Silva, D. H., \& Sell, D. (2021). Isolamento social e a velocidade de casos de COVID-19: medida de prevenção da transmissão. Revista Gaúcha de Enfermagem, 42, e20200238.

Souza, A. F., \& Miranda, A. C. O. (2018). Os problemas causados pelo uso excessivo de smartphones [The Problems Caused by Excessive Use of Smart Phones]. Instituto Federal do Ceará Campus Caucaia.

Średniawa, A., Drwiła, D., Krotos, A., Wojtaś, D., Kostecka, N., \& Tomasik, T. (2019). Insomnia and the Level of Stress among Students in Krakow, Poland. Trends in Psychiatry and Psychotherapy, 41, 60-68. https://doi.org/10.1590/2237-6089-2017-0154

U.S. Department of Health and Human Services (2018). Physical Activity Guidelines for Americans (2nd ed.). Washington DC: U.S. Department of Health and Human Services.

Voitsidis, P., Gliatas, I., Bairachtari, V., Papadopoulou, K., Papageorgiou, G., Parlapani, E. et al. (2020). Insomnia during the COVID-19 Pandemic in a Greek Population. Psychiatry Research, 289, Article ID: 113076. https://doi.org/10.1016/j.psychres.2020.113076

World Health Organization (2020). Mental Health and Psychosocial Considerations during the COVID-19 Outbreak. Geneva: WHO.

https://www.who.int/docs/default-source/coronaviruse/mental-health-considerations.pdf

Wright Jr., K. P., Linton, S. K., Withrow, D., Casiraghi, L., Lanza, S. M., Iglesia, H. et al. (2020). Sleep in University Students Prior to and during COVID-19 Stay-at-Home Orders. Current Biology, 30, R797-R798. https://doi.org/10.1016/j.cub.2020.06.022

Zhang, W. R., Wang, K., Yin, L., Zhao, W. F., Xue, Q., Peng, M. et al (2020). Mental Health and Psychosocial Problems of Medical Health Workers during the COVID-19 Epidemic in China. Psychotherapy and Psychosomatics, 89, 242-250. https://doi.org/10.1159/000507639

Zhang, Y., Zhang, H., Ma, X., \& Di, Q. (2020). Mental Health Problems during the COVID-19 Pandemics and the Mitigation Effects of Exercise: A Longitudinal Study of College Students in China. International Journal of Environmental Research and Public Health, 17, 3722. https://doi.org/10.3390/ijerph17103722 